\title{
The aging impact on the cooling capacity of a natural ester used in power transformers
}

\author{
A. Ortiz, F. Delgado, Félix Ortiz, Inmaculada Fernández, Agustín Santisteban \\ Department of Electrical and Energy Engineering \\ ETSI Industriales y T. University of Cantabria \\ Av. Los Castros s/n, 39005 Santander, Spain \\ e-mail: ortizfa@unican.es
}

\begin{abstract}
In this paper, an experimental and numerical research was conducted to study the aging effect on the cooling performance of a natural ester habitually used in power transformers. A monitored experimental platform has been used to observe the temperature increases with the aging of the ester. Three samples with three aging levels (fresh oil, aged oil and aged oil with paper) were tested at three load levels, $C=0.72, C=1$ and $\mathrm{C}=1.3$ (9 tests). The two aged samples (6 liters each) were aged in an accelerated way within an oven: 1 week at $150^{\circ} \mathrm{C}$. Also, some physicochemical properties of the insulation system were determined. In the case of the liquid, viscosity, moisture, acidity, dissipation factor $\left(90^{\circ} \mathrm{C}\right)$ were measured. The degree of polymerization and the moisture were measured in paper samples. A 2D numerical model has been developed with COMSOL Multiphysics to replicate the thermal-hydraulic behavior of the samples in the platform. That is, the idea is to determine the temperature and velocity distributions of the different samples in order to analyze their differences and to compare their cooling capacity. At first sight, the aging affects negatively to the cooling capacity of the new alternative liquid based on natural esters.
\end{abstract}

Keywords - natural ester; thermal aging; PSP paper, experimental platform, $2 D$ numerical model, cooling capacity

\section{INTRODUCTION}

Currently, mineral oil is commonly used as a dielectric and coolant liquid in power transformers worldwide. In these devices, Joule losses heat the windings and the fluid cools them circulating through channels arranged among conductors. The main goal of the cooling is to prevent excessive temperatures in these conductors, i.e. to avoid the appearance of hot-spots (hottest temperature areas in the conductors in contact with solid insulation, mainly paper or cardboard) since the aging of the paper is sensible to temperature. In fact, according to IEC 60076-7 standard, an increase of $6{ }^{\circ} \mathrm{C}$ doubles the insulation ageing rate, reducing the lifespan of the device, [1]. For this reason, several theoretical and experimental techniques have been traditionally used by manufacturers and customers to determine the oil flow pattern, temperatures distribution and the location and value of the hot-spots in the windings, [2]. Among the former, Computational Fluid Dynamics (CFD) modelling is relatively recent in comparison with other such as Thermal-Hydraulic Network Modelling (THNM). CFD characterizes in fine detail the flow and temperature distributions at the expense of being more demanding in computational requirements and more time consuming than THNM.

Despite its disadvantages, CFD technique has been used since the beginning of the twenty-first century to model the thermal-fluid behaviour of mineral oil flowing through the windings. For instance, Mufuta et al. and El Wakil et al. modelled two windings using this technique in first decade of the millennium. The former characterizes the oil flow through an array of discs with different spaces between discs and different inlet conditions, [3]. The latter employed a 2D axisymmetric model of a power transformer with six different geometries and six different inlet velocities in order to study the heat transfer and oil flow through the windings, [4]. In the current decade, other authors have contributed to this labour. For instance, Torriano performed 2D and 3D simulations of a Low Voltage Winding (LVW) of a power transformer with zigzag cooling to determine the effects of several elements, such as sticks and inter-sticks, in the temperature distribution, [5, 6]. In 2011, Gastelurrutia et al. carried out a study where they developed a 3D and a 2Dmodel of an Oil Natural-Air Natural (ONAN) distribution transformer. They demonstrated the good capacity of the simplified 2D model to represent the thermal behaviour of the whole transformer, [7]. In 2012, Tsili et al. established a methodology to develop a 3D-model and to predict hot-spot temperature, [8]. In this year, Skillen et al. carried out a CFD simulation of a 2D non-isothermal flow axisymmetric model in order to characterize the oil flow in a transformer winding with zigzag cooling, [9]. In 2014, Yatsevsky carried out a 2D-axisymmetric simulation of an oil-immersed transformer with natural convection, including the core, the tank and the radiator, in order to predict hot-spots. The developed model showed a good adequacy verified by experiments, [10]. Recently, Torriano et al. has developed a 3DConjugate Heat Transfer model of an ON disc-type power transformer winding scale model. An 
underestimation of the average and hot-spot temperatures was obtained in this model in comparison with the experimental setup when the entire cooling loop was considered. This is the reason why the authors chose to reduce the computational domain to the winding, setting the inlet boundary conditions. This way, the model accuracy was improved significantly, [11].

In spite of all the research that is being carried out about the mineral oil as a coolant and also as a dielectric liquid, there is an increasing interest in its substitution by new biodegradable fluids with higher ignition points. Natural esters are one type of these alternative liquids. Nonetheless, tests have to be done to ensure the performance of these fluids from all points of view. For instance, as in the case of mineral oil, their cooling capacity (i.d. measure of a cooling system's ability to remove heat) have to be verified. In fact, several authors have carried out this labor comparing different types of alternative liquids with mineral oil in different cooling systems. For instance, in 2015, Park and Han compared the temperatures distribution and the hot-spots values and their location of three dielectric liquids (a natural and a synthetic esters and a mineral oil) in a 2D numerical model of a zigzag cooling system, [12]. In the same year, Lecuna et al. performed the same work using a 3D numerical model of an axial cooling system with three types of alternative dielectrics liquids. Two cooling indexes (convective heat transfer coefficient $(\mathrm{h})$ and the cooling criterion (P)) were also calculated, [13]. These works concluded that alternative liquids produce higher temperatures in the transformer windings designed for mineral oil. More recently, Santisteban et al. evaluated the cooling performance of two alternative natural liquids with that of a typical mineral oil. This task was carried out using a 2D-axisymmetric model of a LVW with zigzag cooling in which temperature distributions, hot-spot temperatures and their locations, and hot-spot factors were determined. In contrast to the results of the previous works, this work shows that the hot-spot temperature is lower for the natural oils than that of mineral oil, [14].

All the works mentioned in the two previous paragraphs consider thermal properties of fresh dielectric liquids. That is, the values of the thermal-fluid properties (viscosity, $\mu$, density, $\rho$, heat capacity, $C_{p}$, and thermal conductivity, $k$ ) are those of the fresh oils and do not vary. However, in the operation of a power transformer, these properties are affected over time for different factors such as the aging or moisture content, [15]. In fact, many experimental results of the variation of the viscosity with the aging can be found for several dielectric liquids in the literature, [16-21]. These works compare the viscosity variation of different types of natural ester-based oils with a mineral oil during thermal aging. However, the influence of this variation on the cooling capacity of the liquid is not determined. The only work that studies this topic was published by Kassi et al. In 2016, they carried out an experimental and numerical analysis using mineral oil as a coolant. The results of a 2D axisymmetric numerical model of a 3-phase power transformer column comparing fresh with aged oil showed the worsening of the cooling capacity with aging, thus resulting in an increase of the hot-spot temperature, [22]. Nevertheless, the effect of the thermal aging on cooling capacity of the natural esters it has not been evaluated yet.

Based on the above, this paper presents a numerical and experimental study of the cooling capacity of a commercial natural ester with three levels of aging. Temperature variations with the degradation of the oil are obtained in an experimental platform. Also, a 2D numerical study of this experimental setup has been developed to determine its temperature and velocity distributions.

First sections of this paper present the experimental work: thermal-aging of the samples and determination of their physicochemical properties are described in section II; the experimental setup is shown in section III. Then, the numerical model developed is presented in section IV. Model validation and its results are presented in section V and VI, respectively. Finally, in section VII, some conclusions are drawn from the experimental and numerical results obtained.

\section{THERMAL AGING AND PHYSICOCHEMICAL PROPERTIES MEASUREMENT}

The aging procedure followed in this paper is described in subsection A. The methodology applied to determine the properties of the liquids and the paper, used both as insulation system, and the values obtained are presented in subsection B.

\section{A. Aging method}

The assessment of the evolution of thermal, electrical or mechanical properties in electrical insulating materials requires long periods of time, which are not feasible under the point of view of time and costs. For this reason, accelerated ageing tests in laboratory are needed to obtain useful information. Currently, ageing procedures and evaluation of test results of electrical insulating materials are described in the standard IEC 60216-1:2013, [23].

In order to evaluate the effect of thermal aging on the cooling capacity of a commercial natural ester, the temperature distribution in a stainless-steel casing containing insulating oil with different degree of aging 
and a 1-phase transformer was assessed. During these tests three types of aged oil samples were studied. The first one was a fresh oil which has not suffered any kind of thermal stress. The second sample of oil was obtained through an accelerated thermal aging test in which the natural ester was thermally aged without any additional material. Finally, the last type of oil was obtained by thermal aging of the natural ester based oil and pressboard 3055 (PSP 3055) strips, see Fig. 1.

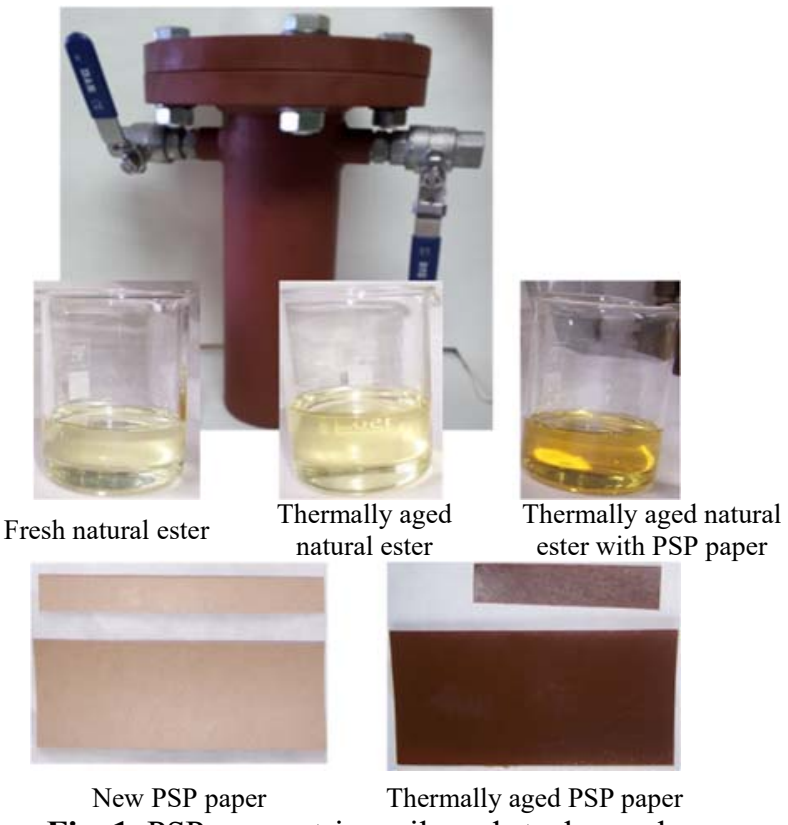

Fig. 1. PSP paper strips, oils and steel vessel

Six vessels for each sample of aged oil were prepared by inserting $1000 \mathrm{ml}$ of natural ester with a nitrogen headspace of $25 \%$ by volume, and $150 \mathrm{~g}$ of PSP 3055 in the case of the third sample of oil. The thermal ageing was then carried out at $150^{\circ} \mathrm{C}$ for 168 hours, see Fig. 2 . After aging time, the vessels were cooled at room temperature $\left(25^{\circ} \mathrm{C}\right)$ for five hours.

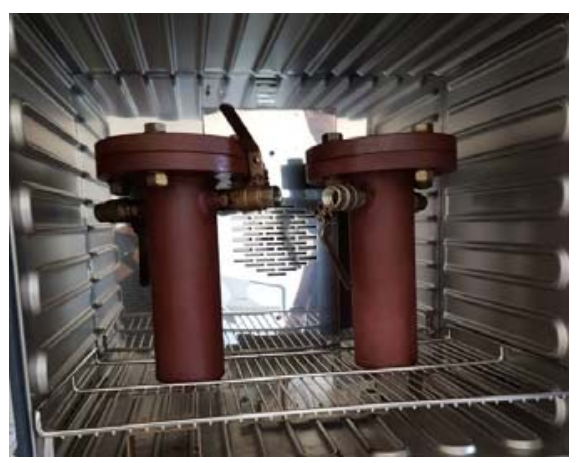

Fig. 2. Oven with vessels.

Regarding the oil aged with PSP 3055, this insulating solid was previously dried under vacuum at 100 ${ }^{\circ} \mathrm{C}$ for one day in the steel vessels, obtaining solid samples with a moisture content of $2.5 \%$.

\section{B. Experimental determination of the physicochemical properties of samples}

Small quantities of the oil samples are taken to evaluate their dynamic viscosity since the heat carrier capacity of these fluids strongly depends on this property. In fact, the variation of the property with the temperature is determined. Other properties related with the thermal performance of samples (density, heat capacity and thermal conductivity) are obtained from the natural ester manufacturer. Also, the paper degradation is tested to assure the aging time was enough to achieve a degree of polymerization (DP) next to 200 which is considered as an end of life criteria, [24]. Finally, other properties related to the degree of aging are evaluated, such as moisture, acidity and dissipation factor in ester, as well as moisture in paper.

1) Dynamic viscosity

The dynamic viscosity is measured with a $\mathrm{HAAKE}^{\mathrm{TM}}$ Viscotester $^{\mathrm{TM}} 550$ rotational viscometer. This viscometer operates in the range temperature of 20 to $100{ }^{\circ} \mathrm{C}$ and generates viscosity data between 1 and $100000 \mathrm{mPa} \times \mathrm{s}$. The method applied to get these data is based on the standard ISO 3219:1993, [25]. 


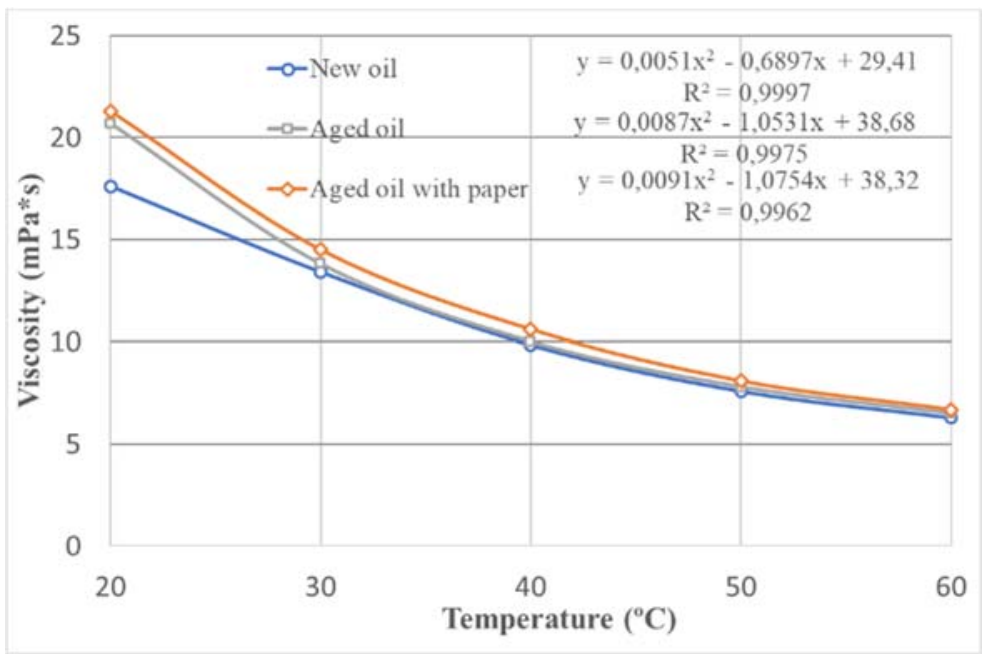

Fig. 3. Dynamic viscosity evolution with the temperature.

As can be seen in Fig. 3, the higher the aged oil degradation, the higher the viscosity. Also, the viscosities of the two aged oils are similar. Nonetheless, it is needed to point out that the difference between viscosities diminish with the temperature.

\section{2) Degree of polymerization}

The method most commonly used for characterizing cellulose degradation is the degree of polymerisation (DP) which was determined according to the standard ASTM D4243-16, [26], by measuring the kinematic viscosity of the paper in solution (the viscosity is related to the molecular weight by the MarkHouwink Sakurada equation). The viscosity-average DP was obtained based on measurements at $20^{\circ} \mathrm{C}$ using an automatic viscometer equipped with a two-sphere Ubbelohde tube. Each paper strip was first deoiled using distilled hexane. Subsequently, the paper was shredded and dissolved in a solution of deionised water and bis(ethylenediamine) copper (II) hydroxide. After dissolution of the paper in the prepared solution, its specific viscosity was determined. From this result, the intrinsic viscosity of the solution was deduced, and from this data the DP was obtained. For this, it is necessary to know the moisture of the sample, which was determined using Karl Fischer titration according to the standard [27].

This methodology was carried out to analyze the degradation suffered by PSP 3055 at $150^{\circ} \mathrm{C}$ along the time. The DP of the paper immersed in natural oil was reduced from 573 to 249 in only 168 hours ( 1 week). Therefore, at this temperature, the insulating solid suffered an important thermal stress, as well as the natural ester.

\section{3) Other properties}

Other properties were determined before and after the aging procedure. The standard followed for the determination of moisture, acidity and dissipation factor can also be seen in the Table 1.

\section{Table 1}

Properties of natural ester and paper, before and after ageing.

\begin{tabular}{lccc}
\hline Parameter & $\begin{array}{c}\text { Initial } \\
\text { value }\end{array}$ & Value after aging & Standard \\
\hline Paper moisture (\%) & 2.5 & 0.42 & IEC 60814 [27] \\
Oil moisture (ppm) & 437 & 1151 & IEC 60814 [27] \\
Acidity (mg/g) & 0.05 & 5.24 & IEC 62021-1 [28] \\
Dissipation factor $\left(90^{\circ} \mathrm{C}\right)$ & 0.03 & 0.6215 & IEC 60247 [29]
\end{tabular}




\section{EXPERIMENTAL SETUP}

The experiment developed is based on that used by Patel et al. to determine the cooling performance of a ferrofluid in a prototype distribution transformer, [30]. As shown in Fig. 4.a, the three samples (about six liters each) are poured in a stainless-steel casing whose dimensions are $20 \times 20 \times 20 \mathrm{~cm}^{3}$, approximately. Then, the 1-phase transformer (800VA, 230/115V), shown in Fig. 4.b, is immersed in the casing. The temperatures inside the tank are monitored by means of three probes (see Fig. 4.b and pentagons in Fig. 5). Two of them are located in the bottom and in the top of the tub to measure the oil temperature (pentagons 1 and 2 in Fig. 5). Other sensor measures the hot-spot winding temperature. According to the standard IEC $60076-2: 2011$, [31], this temperature is defined as the hottest temperature of winding conductors in contact with solid insulation or insulating liquid. This sensor is located at the top of the winding since it is very probable that the hot-spot will be in this place (pentagon 3 in Fig. 5). Ambient temperature is also measured to use it as a reference (pentagon 4 in Fig. 5). A microcontroller (Arduino) and an Integrated Development Environment (IDE) is used to capture and to record the measurements of the sensors.

Using this platform, several short circuit tests have been carried out in which three load level cases $(\mathrm{C}=0.72, \mathrm{C}=1, \mathrm{C}=1.3)$ are considered, with negligible no-load losses, Table 2 . The rated currents of the transformer considered are $3.5 \mathrm{~A}$ in the high voltage winding $(230 \mathrm{~V})$ and $7 \mathrm{~A}(115 \mathrm{~V})$ in the low voltage winding (115V).

\section{Table 2}

Currents in the low voltage winding for each load level considered

\begin{tabular}{cc}
\hline Load Level $(\mathrm{C})$ & Low voltage current $(\mathrm{A})$ \\
\hline Rated regime $=1$ & 7 \\
Overloaded regime $=1.3$ & 9.1 \\
Underload regime $=0.72$ & 5 \\
\hline
\end{tabular}

The heat is only produced by the windings. This heat is evacuated to the air by the commercial natural ester through the stainless-steel walls. As mentioned above, three aging levels of this fluid are tested: fresh and aged oil, and aged oil with paper.

During the tests, the IDE catch the temperatures of the three sensors every five minutes until steady-state is reached. For commercial transformers the stability criteria defined both in the standards [31] and IEEE Std C57.12.90-2015, [32], is a temperature variation of the top oil temperature rise below $1{ }^{\circ} \mathrm{C} \mathrm{h}^{-1}$ over consecutive period of 3 hours. The way the temperature variations must be calculated is not clear in the standards, but this is the criteria adopted to determine the stationary regime. In all the tests, the steady-state regime is reached in 10 to 12 hours, approximately.

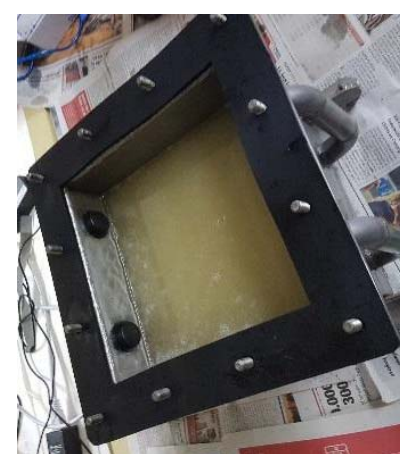

(a) Transformer tank

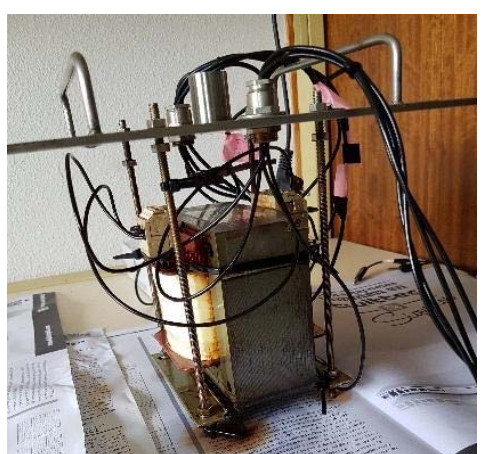

(b) 1-ph transformer

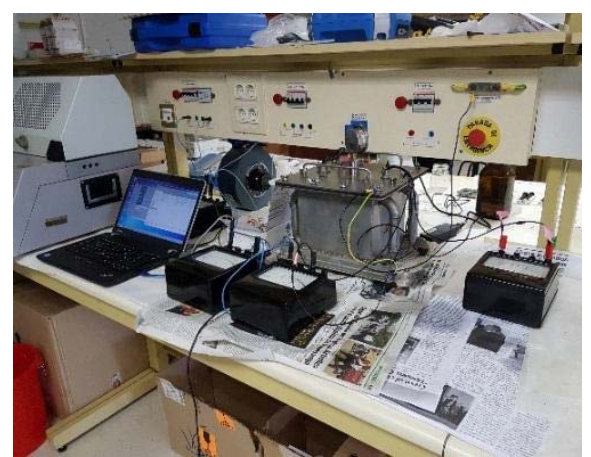

(c) Meas. and monitoring equipment

Fig. 4. Experimental platform.

\section{NUMERICAL MODEL}

This section presents the description of the numerical model that allow us to study the physical phenomena that occur in the experimental platform. This model has been carried out using the software 
tool COMSOL Multiphysics 5.3. Thereby, the governing equations and the boundary conditions of the stationary study applied to 2D section of the platform are presented (see Fig. 5). Also, computational domain, meshing and material properties are shown.

\section{A. GOVERNING EQUATIONS}

This study is based on the numerical solution of the momentum and continuity equations in laminar regime, (1) and (2), respectively. It also solves the heat transfer equation, (3).

$$
\begin{gathered}
\rho(\boldsymbol{u} \cdot \nabla) \boldsymbol{u}=\nabla \cdot\left[-p \boldsymbol{I}+\mu\left(\nabla \boldsymbol{u}+(\nabla \boldsymbol{u})^{T}\right)-\frac{2}{3} \mu(\nabla \cdot \boldsymbol{u}) \boldsymbol{I}\right]+\boldsymbol{F} \\
\nabla \cdot(\rho \mathbf{u})=0 \\
\rho C_{p} \mathbf{u} \cdot \nabla \mathrm{T}=\nabla \cdot(\mathrm{k} \nabla T)+q
\end{gathered}
$$

The symbols $\rho, \boldsymbol{u}, p, \mathbf{I}, \mu, \mathbf{F}, \mathrm{C}_{\mathrm{p}} \mathrm{T}$ and $q$ of (1), (2) and (3) are density, velocity vector, pressure, identity matrix, dynamic viscosity, body force vector (buoyancy forces), specific heat capacity, temperature and unitary heat transfer, respectively.

\section{B. BOUNDARY CONDITIONS}

Several assumptions and simplifications have been considered to obtain the 2D numerical model of the experimental setup. It is needed to point out that the simplifying process is similar to the proposed in [7].

As shown in Fig. 5, several thermal and hydraulic boundary conditions are considered. Also, the constant heat source in the windings (load losses) and the buoyancy forces due to density differences in the liquid are indicated.

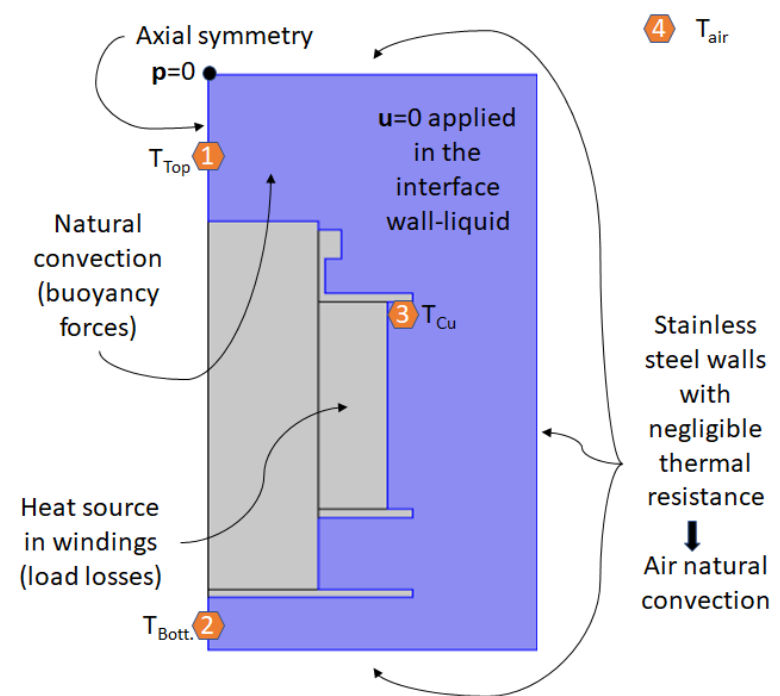

Fig. 5. 2D section of the platform. 


\section{COMPUTATIONAL DOMAIN AND MESH}

The computational domain considers both the liquid and solid part of the geometry to calculate the temperature distribution in the entire model and the fluid behavior in the tank.

Initially, in the meshing study, several mesh types with different meshing densities are studied, thus obtaining several configurations with similar solutions. Finally, a high-density mesh in which free triangular elements are combined with rectangular boundary layers is selected (See Fig. 6). This mesh configuration allows to capture the temperature and velocity boundary layers in the interface solid-liquid and the temperature stratification in the fluid that produce the convection cycles.

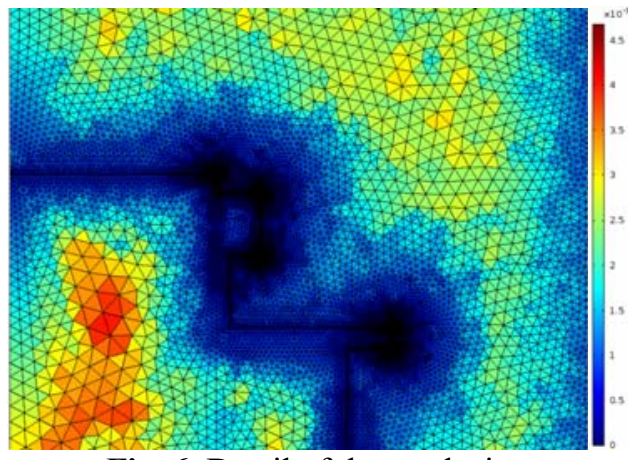

Fig. 6. Detail of the mesh size.

\section{MATERIAL PROPERTIES}

Apart from the oil properties, those of the solid materials of the platform have to be considered in the model. Thereby, Table 3 shows these last properties.

Table 3

Physical properties of solid materials

\begin{tabular}{lccc}
\hline & $\begin{array}{c}\rho \\
{\left[\mathrm{kg} / \mathrm{m}^{3}\right]}\end{array}$ & $\begin{array}{c}\mathrm{k} \\
{[\mathrm{W} /(\mathrm{m} \mathrm{K})]}\end{array}$ & $\begin{array}{c}\mathrm{C}_{\mathrm{p}} \\
{[\mathrm{J} /(\mathrm{kg} \mathrm{K})]}\end{array}$ \\
\hline Copper & 8,960 & 400 & 385 \\
Silicon steel GO 3\% & 7,650 & 30.5 & 460 \\
Acrylic plastic & 1,190 & 0.18 & 1,470 \\
\hline
\end{tabular}

\section{MODEL VALIDATION}

The 2D numerical model has been validated by comparison of the temperatures measured by sensors in the experimental platform with those of the virtual probes used in the model, see Table 4. Obviously, the numerical model tries to replicate the experimental tests as accurately as possible. For instance, the simulations have been carried out using the air temperatures of the experimental tests as boundary condition.

Table 4

Tests vs. model temperatures probes

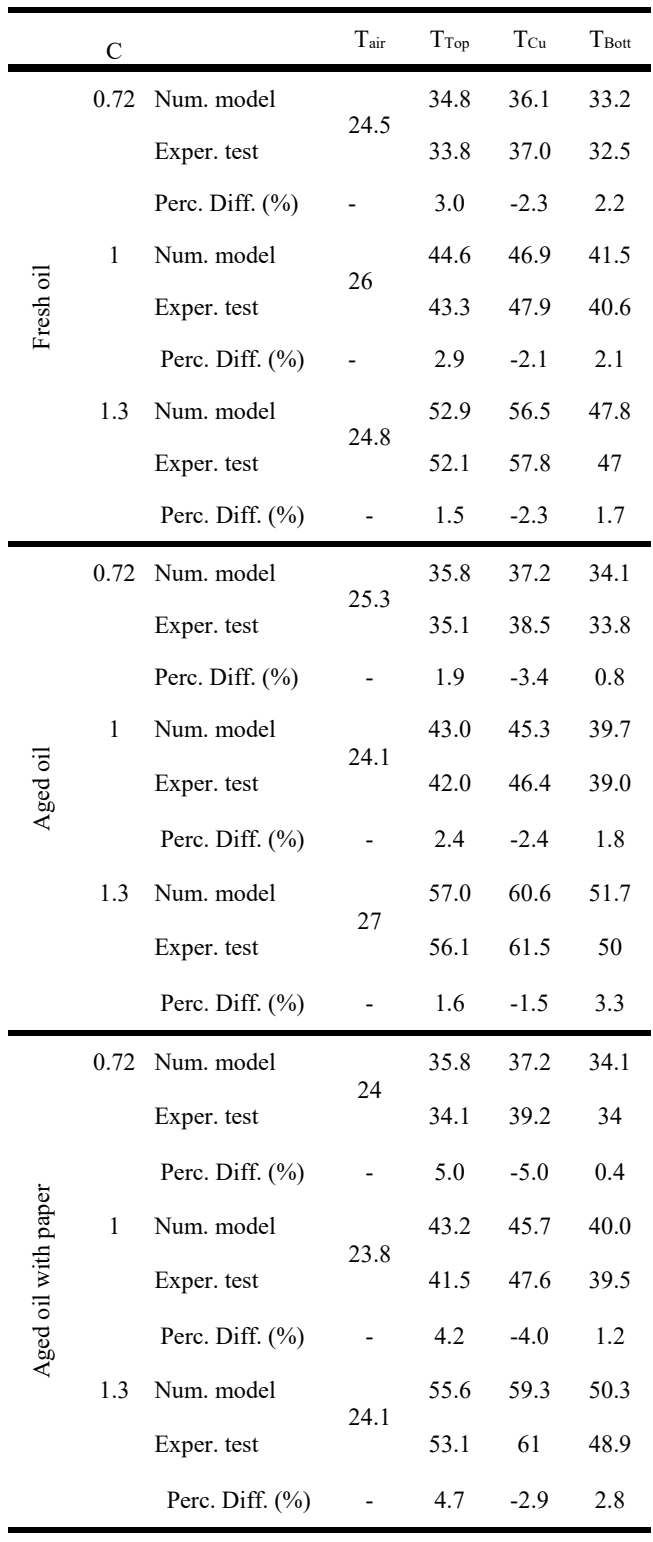

All the errors of the virtual probes regarding platform sensors are within the range \pm 5 . This way, the model is accurate enough to use it in the determination of the thermal-hydraulic behavior of the liquids.

\section{RESULTS}

\section{A. EXPERIMENTAL RESULTS}

Table 5 shows the temperature increments regarding ambient temperature measured in the experimental tests. As it can be seen in this table, from the oil cooling capacity standpoint, its aging worsens this capability: considering the same load index, the higher the aging, the higher the temperatures at the top and bottom of the tank. This clearly affects to the hot-spot winding temperature, increasing also with the aging, Fig. 8. Also, considering the same sample, it is also remarkable that the higher percentage increment of the 
winding temperature correspond to the smallest load index. This is mainly due to the exponential decrement of the viscosity with the temperature, see Fig. 3 and 7. In this last Figure, the percentage increase is calculated using the fresh oil temperature increase as reference for each load index.

Apart from the higher temperature gradients with underload regime, their worst cooling capacity can be appreciated in the difference $\mathrm{T}_{\mathrm{Top}}-\mathrm{T}_{\text {Bott, }}$ (right column in Table 5): the lower the load index, the lower the difference. Also, among these three cases, the one with the lowest load index is the worst, since this case combines the most degraded liquid with the lowest temperatures, thus having the highest viscosity. This can be explained by the smaller vertical stratification of the oil temperatures that occur in the samples with the higher viscosities.

Table 5

Experimental temperatures gradients

\begin{tabular}{|c|c|c|c|c|c|}
\hline $\mathrm{C}$ & Aging & $\Delta \mathrm{T}_{\mathrm{Top}}$ & $\Delta \mathrm{T}_{\mathrm{Cu}}$ & $\Delta \mathrm{T}_{\text {Bott }}$ & $\begin{array}{l}\mathrm{T}_{\text {Top }}- \\
\mathrm{T}_{\text {Bott }}\end{array}$ \\
\hline \multirow{3}{*}{0.72} & Fresh & 9.3 & 12.5 & 8.0 & \\
\hline & Aged & 9.8 & 13.2 & 8.5 & \\
\hline & Aged w/p & 10.1 & 15.2 & 10.0 & 0.1 \\
\hline \multirow{3}{*}{1} & Fresh & 17.3 & 21.9 & 14.6 & \\
\hline & Aged & 17.9 & 22.3 & 14.9 & \\
\hline & Aged w/p & 17.7 & 23.8 & 15.7 & 2.0 \\
\hline \multirow{3}{*}{1.3} & Fresh & 27.3 & 33 & 22.2 & \\
\hline & Aged & 29.1 & 34.5 & 23.0 & \\
\hline & Aged w/p & 29.0 & 36.9 & 24.8 & 4.2 \\
\hline
\end{tabular}

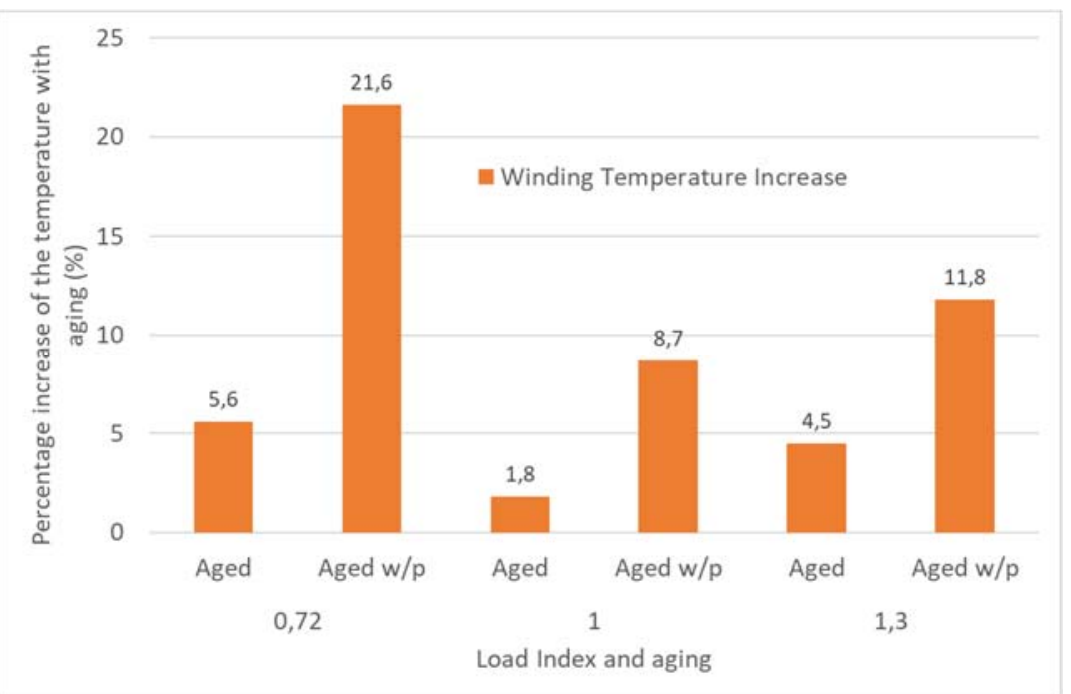

Fig. 7. Effect of ageing on the winding temperature

\section{B. NUMERICAL RESULTS}

As can be seen in Fig. 8, the last assertion has been corroborated by the numerical model: the higher the load index, the higher the vertical thermal stratification. Furthermore, this effect can be seen in the difference between the hot-spot and the minimum temperature of the oil. This difference will be increased with the load index. Finally, the increase of thermal stratification with temperature results in an increase in the number of convection cycles, thus improving the cooling capacity of the fluid. 


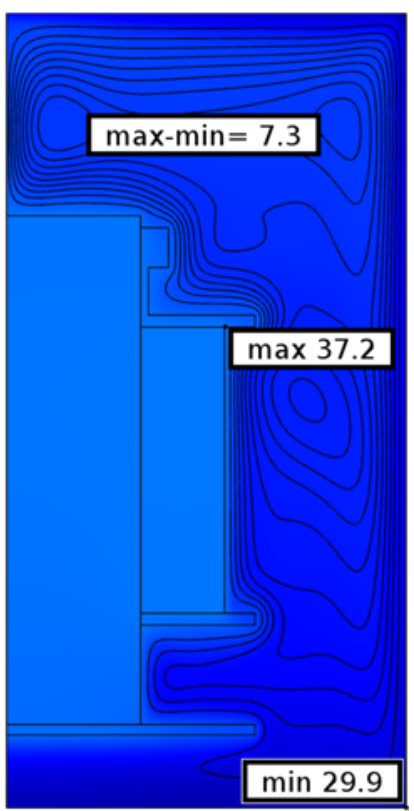

Worst case, $\mathrm{C}=0.72$

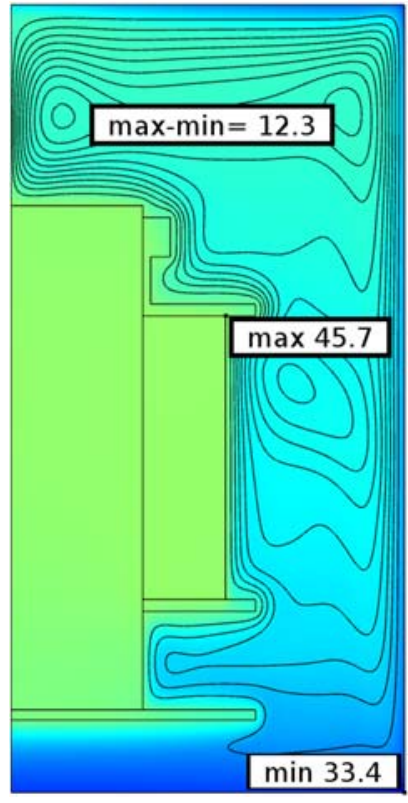

Intermediate case, $\mathrm{C}=1$

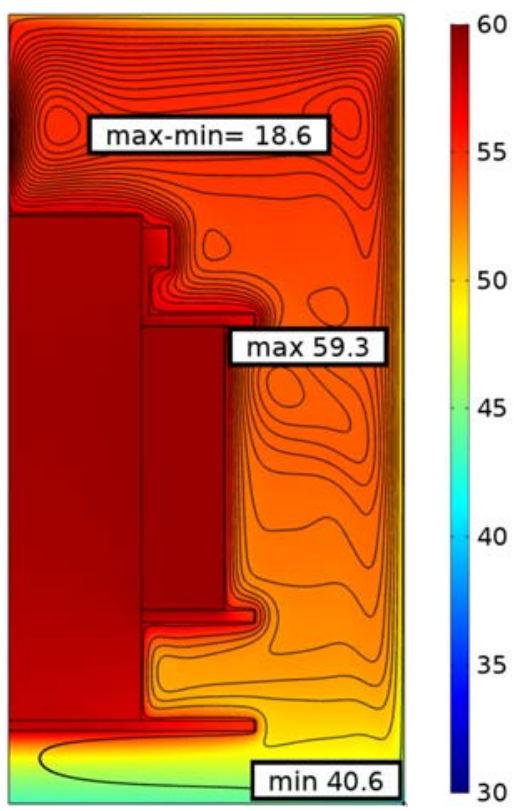

Base case, $\mathrm{C}=1.3$

Fig. 8. Thermal stratification and flow pattern of aged oil with paper $\left({ }^{\circ} \mathrm{C}\right)$

The level of vertical thermal stratification can be also seen in the rotational velocity of the oil in these cycles, as shown in Fig. 9. An ordered movement of the oil in horizontal layers can be observed in the figure previously mentioned. However, the higher the vertical thermal stratification, the greater the oil velocity and the "disorder" in the fluid, improving this way the cooling capacity of the fluid.

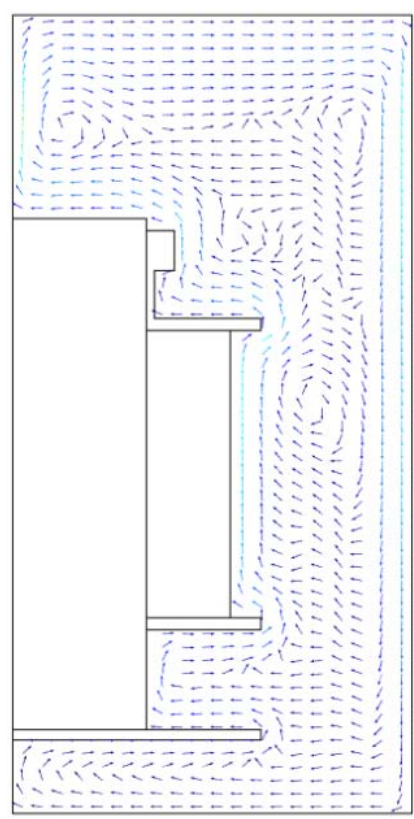

Worst case, $\mathrm{C}=0.72$

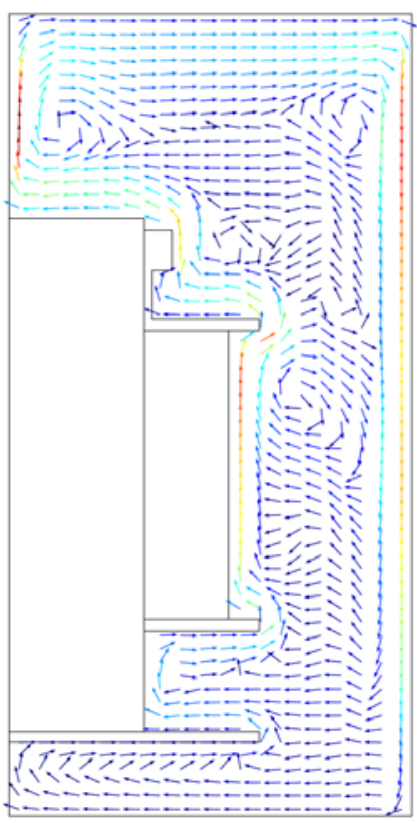

Intermediate case, $\mathrm{C}=1$

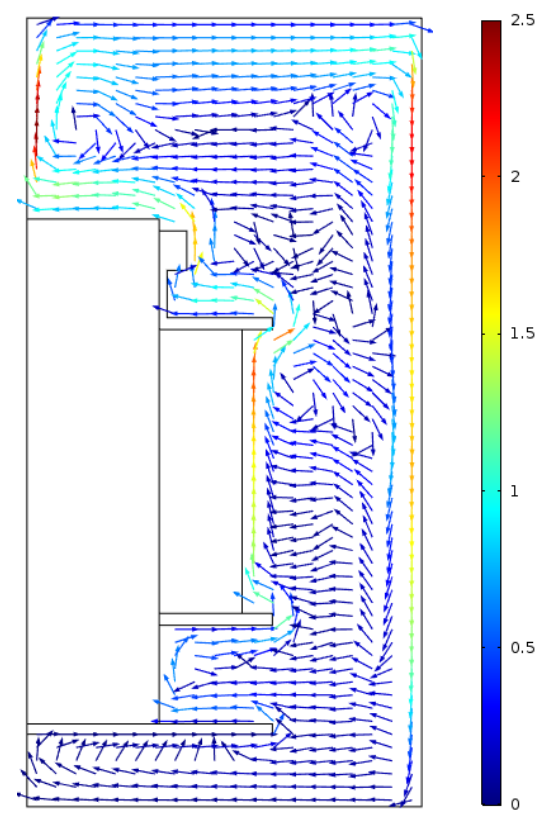

Best case, $\mathrm{C}=1.3$

Fig. 9. Velocity pattern of aged oil with paper cases $(\mathrm{mm} / \mathrm{s})$

\section{CONCLUSIONS}

An experimental and numerical study of the cooling capacity of a biodegradable dielectric liquid is presented in this paper. The aging method of this liquid is also described. Also, some physicochemical properties of the oil and paper used in the experimental platform are determined.

Nine experimental tests and their respective simulations have been carried out and compared. As a result of this comparison, the numerical model has been validated. 
The experimental results indicate that the cooling capacity of the alternative liquid worsens with aging. This is due to the higher viscosity of the aged samples. However, this negative effect is mitigated by the load index; in fact, by the operating temperature: the higher this temperature, the lower the impact of the aging on the cooling capacity. This is due to the exponential decrease of the viscosity with temperature.

All the above has been confirmed numerically. In fact, the model captures the variation of the vertical thermal stratification and the increasing number of convection cycles.

From the point of view of the applicability of the previous results, it must be taken into account that the use of natural esters in power transformers is increasingly frequent. Currently, the number of equipment insulated with these liquids is estimated close to 1.5 million worldwide, mainly in electric distribution systems. For instance, there is already more than 12 years of experience in its application in the Brazilian electric power distribution systems. Nonetheless, in these transformers, the temperature is only monitored in the top oil of the tank or in the winding, indirectly by thermal image. At this point, it is worth mentioning the project that has just started the Italian transmission system operator to incorporate these biodegradable liquids to power transformers connected to its $420 \mathrm{kV}$ network. The windings temperatures of these transformers will be monitored by fiber-optic sensors. Thus, the knowledge of the state of these machines is vital for their owners and for this reason the dielectric liquids are monitored to control their temperatures and ensure reliable operation of these equipment. In this regard, the International Electrotechnical Commission is currently drafting the document IEC 62975, which will provide guidelines for maintenance and use of natural esters in electrical equipment. This document already exists in draft form, although it is not officially published.

The study presented here will complement the future standard and will help to understand how the cooling capacity of natural esters varies with their aging. It will also serve to know how the hot-spot temperature is affected with this degradation since the lifespan of a power transformer is crucially affected by this value. Therefore, this study will support the decisions of transformers fleet managers using natural esters, facilitating that these machines provide optimum service.

\section{ACKNOWLEDGEMENT}

The research leading to these results has received funding from multiple sources over years, but we would specifically like to acknowledge the support received in the later stages from the Spanish Plan Estatal de I+D under the grant agreement DPI215-71219-C2-1-R.

\section{REFERENCES}

[1] IEC 60076-7:2018: Power Transformers. loading guide for mineral-oil-immersed power transformers. British Standards Institute, Feb 14, (2018).

[2] R. Bouhaddiche, S. Bouazabia, I. Fofana, Thermal modelling of power transformer. IEEE, 19th Int. Conf. Dielect. Liquids (ICDL), (2017), doi: 10.1109/ICDL.2017.8124676.

[3] J. Mufuta, E. Van Den Bulck, Modelling of the mixed convection in the windings of a disc-type power transformer. Appl. Therm. Eng. 20 (2000) 417-437, doi: 10.1016/S1359-4311(99)00034-4.

[4] N.E. Wakil, N. Chereches, J. Padet, Numerical study of heat transfer and fluid flow in a power transformer. Int. J. Therm. Scien, 45 (2006) 615-626, doi 10.1016/j.ijthermalsci.2005.09.002.

[5] F. Torriano, M. Chaaban, P. Picher, Numerical study of parameters affecting the temperature distribution in a disc-type transformer winding. Appl. Therm. Eng. 30 (2010) 2034-2044. doi: 10.1016/j.applthermaleng.2010.05.004

[6] F. Torriano, P. Picher, M. Chaaban, Numerical investigation of 3D flow and thermal effects in a disctype transformer winding. Appl. Therm. Eng. 40 (2012) 121-131, doi:

10.1016/j.applthermaleng.2012.02.011.

[7] J. Gastelurrutia, J.C. Ramos, G.S. Larraona, A. Rivas, J. Izagirre, L. del Río. Numerical modelling of natural convection of oil inside distribution transformers. Appl. Therm. Eng. 31 (2011) 493-505, doi: 10.1016/j.applthermaleng.2010.10.004.

[8] M.A. Tsili, E.I. Amoiralis, A.G. Kladas, A.T. Souflaris, Power transformer thermal analysis by using an advanced coupled 3D heat transfer and fluid flow FEM model. Int. J. Therm. Scien, 53 (2011) 188201, doi: 10.1016/j.ijthermalsci.2011.10.010.

[9] A. Skillen, A. Revell, H. Iacovides, W. Wu, Numerical prediction of local hot-spot phenomena in transformer windings. Appl. Therm. Eng. 36 (2012) 96-105, doi: 10.1016/j.applthermaleng.2011.11.054. 
[10] V.A. Yatsevsky, Hydrodynamics and heat transfer in cooling channels of oil-filled power transformers with multicoil windings. Appl. Therm. Eng. 63 (2014) 347-353, doi:

10.1016/j.applthermaleng.2013.10.055.

[11] F. Torriano, Numerical and experimental thermofluid investigation of different disc-type power transformer winding arrangements. Int. J. Heat Fluid Flow, 69 (2018) 62-72, doi:

10.1016/j.ijheatfluidflow.2017.11.007.

[12] T. Park, Numerical analysis of local hot-spot temperatures in transformer windings by using alternative dielectric fluids. Electr. Eng. 97 (2015) 261-268, doi: 10.1007/s00202-015-0335-4.

[13] R. Lecuna, F. Delgado, A. Ortiz, P.B. Castro, I. Fernandez, C.J. Renedo, Thermal-fluid characterization of alternative liquids of power transformers: a numerical approach. IEEE Transac.

Dielectr. Electr. Insul. 22 (2015) 2522-2529, doi: 10.1109/TDEI.2015.004793.

[14] A. Santisteban, F. Delgado, A. Ortiz, I. Fernández, C.J. Renedo, F. Ortiz, Numerical analysis of the hot-spot temperature of a power transformer with alternative dielectric liquids. IEEE Transac. Dielectr. Electr. Insul. 24 (2017) 3226-3235, doi: 10.1109/TDEI.2017.006228.

[22] K.S. Kassi, M.I. Farinas, I. Fofana, C. Volat, Analysis of aged oil on the cooling of power transformers from computational fluid dynamics and experimental measurements. J. Appl. Fluid Mech. 9 (2016) 235-243, .

[23] IEC 60216-1:2013 Electrical insulating materials - thermal endurance properties - part 1: ageing procedures and evaluation of test results.

[24] M.C. Lessard, T.K. Saha, V. Sokolov, A. Pablo, Ageing of cellulose in mineral-oil insulated transformers. Technical Brochure 323, D1.01.10, (2007).

[25] ISO 3219:1993 Plastics. Polymers/Resins in the Liquid State Or as Emulsions Or Dispersions. Determination of Viscosity using a Rotational Viscometer with Defined Shear Rate.

[26] ASTM D4243-16. Standard test method for measurement of average viscometric degree of polymerization of new and aged electrical papers and boards, ASTM International, West Conshohocken, PA, (2016).

[27] IEC 60814:1997. Insulating liquids - oil-impregnated paper and pressboard - determination of water by automatic coulometric Karl Fischer titration.

[28] IEC 62021-1:2003. Insulating liquids - Determination of acidity - Part 1: Automatic potentiometric titration.

[29] IEC 60247:2004. Insulating liquids - Measurement of relative permittivity, dielectric dissipation factor $(\tan d)$ and d.c. resistivity.

[30] J. Patel, Performance of Mn-Zn ferrite magnetic fluid in a prototype distribution transformer under varying loading conditions. Int. J. Therm. Scien, 114 (2017) 64-71, doi:

10.1016/j.jijthermalsci.2016.12.011

[31] IEC 60076-2:2011. Power transformers - Part 2: Temperature rise for liquid-immersed transformers (2011).

[32] IEEE Std C57.12.90-2015 (Revision of IEEE Std C57.12.90-2010): IEEE Standard Test Code for Liquid-Immersed Distribution, Power, and Regulating Transformers. IEEE, (2016). 